\title{
ПРОЕКТЫ ГОСУДАРСТВЕННО-ЧАСТНОГО ПАРТНЕРСТВА В СЕВЕРО-ЗАПАДНОМ ФЕДЕРАЛЬНОМ ОКРУГЕ. ИННОВАЦИИ В УПРАВЛЕНИИ
}

\section{О.Д. УГОЛЬНИКОВА}

к.ф.м.н., доцент кафедры «Менеджмент таможенного и страхового сервиса» ФГБОУ ВО «СПбГЭУ», факультет региональной экономики и управления

Статья подготовлена в ралках реализащии проекта 2.2.5 «Проведение научных исследований в сфере потребительских, таможенных и криминалистических услуг населению в рамках научно-образовательного центра «Технологии товароведческой,таможенной $u$ криминалистической экспертизы» Программы стратегического развития ФГБОУ ВПО «СПбГЭУ» на 2014-2016 годы.

\section{Аннотация}

В научной статье автор рассмотрел теоретические, правовые, управленческие аспекты государственно-частного партнерства, его формирование и развитие в Северо-Западном Федеральном округе - регионе-лидере инновационного развития российских территорий.

Ключевые слова: государственно-частное партнерство, конкурентная среда, регион, развитие территорий.

Abstract

The author has examined the theoretical, legal and administrative aspects of public-private partnership, its formation and development in the North-West Federal District. This is the region leader of innovative development of Russian territories.

Keywords: public-private partnership, the competitive environment, the region, the development of territories.

Первые крупные российские проекты типа государственно-частного партнерства начали реализовываться в Санкт-Петербурге. Наиболее известные из них: строительство Западного скоростного диаметра (ЗСД) на основе Федерального закона «О концессионных соглашениях», развитие аэропорта Пулково на основе городского Закона о ГЧП, строительство автомобильных дорог на территории жилого района «Славянка», строительство детских садов и школ в жилых районах «Славянка» и «Новая Ижора», реконструкция Северной водопроводной станции (проект «Невская вода»), строительство завода по переработке твердых бытовых отходов. Ранее планировалось осуществить на условиях ГЧП такие проекты, как строительство Орловского тоннеля под Невой и Дворца искусств на Васильевском острове.

В СЗФО также впервые в России было применено государственно-частное партнерство в развитии социальной инфраструктуры. С 2011 г. Пушкинском районе г. Санкт-Петербурга 
построены и эксплуатируются на условиях ГЧП несколько детских садов и школ. Продолжается строительство новых объектов дошкольного и школьного образования.

Реализацией городской политики в сфере государственно-частного партнерства занимался учрежденный в ноябре 2003 г. Комитет по инвестициям и стратегическим проектам Правительства Санкт-Петербурга и государственное учреждение «Агентство стратегических инвестиций». ГУ «АСИ» с 2004 г. оказывает организационно-техническое содействие в реализации инвестиционных проектов в Санкт-Петербурге, осуществляет девелопмент проектов, подготовку территорий к осуществлению инвестиционной деятельности, технический надзор, выступает организатором конкурсов на основе государственно-частного партнерства.

Региональный закон о государственно-частном партнерстве позволяет Санкт-Петербургу использовать неограниченный перечень схем, что предполагает возможность структурирования проектов с учетом их особенностей, а также определять параметры конкретных проектов в конкурсной документации, поэтому положения закона о ГЧП применимы как к масштабным, так и к небольшим проектам.

В отрасли транспорт, дорожное строительство, наибольший интерес представляет реализация проекта создания и эксплуатации на основе ГЧП бесплатных автомобильных дорог общей протяженностью 7,7 км на территории района «Славянка». Проект не является таким уникальным и сложным, как проект строительства Западного скоростного диаметра. Он служит моделью решения проблем создания (реконструкции) региональных или муниципальных автомобильных дорог общего пользования, которые не реализуемы в рамках схем, предполагающих сбор платы с пользователей.

Целью проекта является обеспечение транспортной доступности нового жилого района «Славянка» Пушкинского района г. Санкт-Петербурга через создание сети бесплатных автомобильных дорог общего пользования и организации их дальнейшего содержания в соответствии с соглашением о государственно-частном партнерстве. В рамках рассматриваемого проекта, в соответствии с соглашением о государственно-частном партнерстве, Санкт-Петербург предоставляет частному партнеру в аренду земельный участок, необходимый для проектирования и строительства автомобильных дорог, а частный партнер за счет собственных и (или) привлеченных средств обязуется выполнить проектирование и строительство автомобильных дорог и осуществлять их эксплуатацию, под которой понимается

- предоставление построенных автомобильных дорог на безвозмездной/бесплатной основе в общее пользование неограниченному кругу лиц. Построенные автомобильные дороги будут квалифицироваться как дороги общего пользования, предназначенные для использования неограниченным кругом лиц. Партнер, являющийся собственником автомобильных дорог с момента их ввода в эксплуатацию, будет по соглашению о ГЧП ограничен в праве на введение платы за проезд и в возможности перевода указанных автомобильных дорог в автомобильные дороги не общего пользования; 
- осуществление работ по содержанию и текущему ремонту с момента ввода в эксплуатацию. Перечень работ, квалифицируемых в качестве работ по содержанию и текущему ремонту автомобильных дорог общего пользования, приведен в Классификации работ по капитальному ремонту, ремонту и содержанию автомобильных дорог общего пользования и искусственных сооружений на них (утв. приказом Минтранса РФ от 12.11.2007 № 160). Предполагается, что осуществление работ по капитальному ремонту партнером производиться не будет.

Итоги открытого конкурса на создание и эксплуатацию автомобильных дорог на территории жилого района «Славянка» были подведены 10 октября 2012 г. Победителем стала дочерняя структура застройщика района «Славянка» ГК «Балтрос» - «Славдорсервис». Согласно условиям конкурса, за год и два месяца компания-победитель конкурса обязана выполнить за счет собственных и привлеченных средств проектирование и строительство новых объектов транспортной инфраструктуры протяженностью 7,7 км дорог, сметная стоимость которых составляет 1,1 млрд. руб. После сдачи автомобильных дорог в эксплуатацию партнер (в соответствии с очередностью графика ввода в эксплуатацию) в течение десяти лет будет обеспечивать их содержание и обслуживание в соответствии с условиями заключенного соглашения о государственно-частном партнерстве и установленными в нем требованиями к состоянию данных дорог

Источник финансирования работ партнера по содержанию и обслуживанию автомобильных дорог - бюджет Санкт-Петербурга. В соответствии с условиями соглашения о ГЧП, вновь созданные объекты транспортной инфраструктуры с момента их ввода в эксплуатацию будут находиться в частной собственности партнера. Затем в соответствии с условиями соглашения о ГЧП, между Санкт-Петербургом и партнером будет заключен договор купли-продажи (в отношении каждой из автодорог), предусматривающий рассрочку платежей со стороны СанктПетербурга. Таким образом, партнер будет обязан осуществить передачу всего созданного имущества в собственность Санкт-Петербурга на условиях, определенных соглашением о ГЧП и договорами купли-продажи.

В соответствии с условиями договоров купли-продажи, заключаемых во исполнение соглашения о ГЧП, город возмещает партнеру затраты, связанные с созданием объектов, путем оплаты выкупной стоимости объектов и процентов за рассрочку платежа. Основным документом, регламентирующим порядок расчетов между сторонами, является соглашение о ГЧП.

В настоящее время в г. Санкт-Петербург находится в условиях реализации сразу несколько проектов государственно-частного партнерства. Это восемь следующих проектов:

- строительство Орловского тоннеля (проект предполагал прокладку автодорожного тоннеля под Невой протяженностью около одного километра, который соединил бы створ Пискаревского проспекта и Смольную набережную в Санкт-Петербурге). Эксплуатацию тоннеля предполагалось осуществлять на платной основе. Однако, данный проект был отменен Правительством Санкт- 
Петербурга осенью 2012 г. в связи с удорожанием строительства. Данный проект следует отнести к неудачному опыту ЧГП В регионе;

- строительство и эксплуатация автомобильных дорог в жилом районе «Славянка» Проект осуществляется в целях обеспечения жилого района «Славянка» соответствующей транспортной инфраструктурой: автомобильными дорогами от 2-х до 4-х полос движения общей протяженностью 7,7 км; остановками общественного транспорта; регулируемыми и не регулируемыми пешеходными переходами и перекрестками; тротуарами и газонами; системой современного и энергоэффективного уличного освещения. Общий объем инвестиций составил 47740,6 млн. руб., из которых инвестиционный фонд РФ финансирует проект на 33\%, Правительство Санкт-Петербурга - 33\%, частные инвестиции составляют также $33 \%$. Относясь к типу ЧГП-проектов, он осуществляется на региональном уровне, в форме соглашении о ГЧП в отрасли транспорт, автодороги;

- реконструкции аэропорта Пулково, относится к проектам федерального уровня, форма проекта - концессионное соглашение, тип - ГЧП, срок реализации 2010-2013 гг., отрасль транспорт, аэропорты. Проект предполагает развитие и расширение аэропорта Пулково за счет привлечения частных инвестиций, создания высококачественной аэропортовой инфраструктуры и улучшения предоставления услуг в целях соответствия пропускной способности аэропорта современным и перспективным требованиям с учетом роста пассажиропотока и грузооборота в средне- и долгосрочной перспективе. Данный проект финансируется в объеме 55000,0 млн. руб., в том числе - 17000,0 млн. руб. - акционерами, что составляет 32 \% всех инвестиций. Реализация проекта позволит создать на базе аэропорта международный транспортный узел в регионе Балтийского моря и превратить Санкт-Петербург в крупнейший транспортный центр СевероЗападного региона России.

- проект по строительству и эксплуатация мусороперерабатывающего завода в Левашово, предполагает создание завода по переработке твердых бытовых отходов с применением современных технологий в районе поселка Левашово Ленинградской области. Уровень проекта региональный. Форма проекта - соглашение о государственно-частном партнерстве между Администрацией Санкт-Петербурга и частным партером в лице консорциума греческих компаний Helector S.A. - Aktor Concessions S.A. - Aktor S.A было заключено 16 мая 2011 года. Окончание строительства намечено на 2015 год. Отрасль - жилищно-коммунальное хозяйство, отходы. Объем финансирования - 8000,0 млн. руб., 100\% - частные инвестиции.

- строительство мультимодального транспортно-пересадочного узла «Девяткино», относящийся к отрасли транспорт, логистика, относится к разряду планируемых проектов межрегионального уровня, типа ГЧП Форма проекта к настоящему времени еще не определена. Проект предполагает создание международного автовокзала, вынесенного за кольцевую автодорогу, совмещенного с единственной станцией петербургского метрополитена на территории Ленинградской области и с железнодорожной платформой «Девяткино», что позволит снять 
нагрузку с улично-дорожной сети Санкт-Петербурга и создать полноценный современный транспортно-пересадочный узел с перехватывающей парковкой;

- строительство и эксплуатация образовательных учреждений в жилом районе «Славянка», проект относится к типу ГЧП со сроками реализации 2011-2013 гг., регионального уровня, форма соглашение о ГЧП, относящегося к отрасли образование. Проект предполагает строительство и последующую эксплуатацию детских садов и школ на территории жилого района «Славянка» Санкт-Петербурга на основе соглашений о государственно-частном партнерстве между городом и частным партнером. Первая школа начала работу в ноябре 2011 г. Первые два детских сада открылись в январе 2012 г. Управляет объектами УК «Перемена». В октябре 2012 г. был проведен конкурс в отношении двух школ и четырех детских садов. Победитель - компания «СлавДорСервис». В постановлении Правительства Санкт-Петербурга «О предоставлении в 2012 г. субсидий на техническую эксплуатацию (содержание) объектов образования на территории Пушкинского района Санкт-Петербурга» был определен порядок субсидирования инвестора из муниципального бюджета в качестве компенсаций его затрат на техническое обслуживание в качестве реализации соглашения между частным партнером и Правительством Санкт-Петербурга.

- «Невская вода» по реконструкции северной водопроводной станции» - проект типа ГЧП регионального уровня в форме соглашения ГЧП, предполагает проектирование, строительство, реконструкцию объектов водоснабжения Северной водопроводной станции Санкт-Петербурга с их последующим оперированием и увеличением производительности станции с 608 до 800 тыс. м³усут. Отрасль проект - жилищно-коммунальное хозяйство, водоснабжение и водоотведение. Первоначально конкурс на заключение соглашения с частным партнером планировалось провести в начале 2012 г. В связи с изменениями в Федеральной закон «О водоснабжении и водоотведении» дата конкурса перенесена на более поздний срок. Срок реализации проекта составляет 30 лет. Начало строительства и реконструкции объектов СВС - 2015 г., участники Правительство СанктПетербурга, ГУП «Водоканал», объем инвестиций 12000,0 млн. руб.

- Западный скоростной диаметр, самый крупный проект на основе государственно-частного партнерства в сфере дорожного строительства, проект типа ГЧП регионального уровня, отрасль транспорт, автодороги, форма концессионного соглашения со сроком реализации 2004-2014 гг. Предполагает создание платной скоростной автомагистрали для обеспечения автомобильных перевозок пассажиров и грузов по направлениям их наибольшей концентрации и подключение транспортного узла Санкт-Петербурга к сети автомобильных дорог страны. Общая протяженность трассы 46,6 км с участками: Южный (11,50 км. от транспортной развязки с КАД до границы Большого морского порта Санкт-Петербург); Центральный (8,95 км, от Большого морского порта Санкт-Петербург по западной оконечности Васильевского острова, до Северо-Приморской части города), Северный (26,15 км, выходит за пределы городской застройки в Северо-Приморской части города, пересекает КАД и является новым вводом в город автомагистрали Е-18 «Скандинавия»). Заключенное в 2011 г. соглашение о государственно-частном партнерстве предполагает строительство частным партнером Центрального участка ЗСД и осуществление им 
платной эксплуатации всей протяженности трассы, включая капитальные и текущие ремонты, содержание и техническое обслуживание автомагистрали в течение 30 лет. Участники Правительство Санкт-Петербурга, ОАО «Западный скоростной диаметр», ООО «Магистраль Северной Столицы». Объем инвестиций, все из которых относятся к частным, составляют 81000,0 млн. руб. Строительство ЗСМ является стратегическим проектом, связано с развитием транзитивного сообщения на федеральном уровне. Во время работы над проектом был подписан «Меморандум об основных принципах и условиях кредитования проекта создания платной автомобильной дороги «Западный скоростной диаметр». Если в конце 2011 г. Совет Евразийского банка развития (ЕАРБ) кредитовал проект данной дороги в сумме 3 млрд.. руб., то к лету 2012 г. ЕАРБ увеличил сумму кредита до 10 млрд. руб. Частные инвесторы вложат в проект всего 81 млрд. руб.

Сведем данные о проектах, относящихся к типу государственно-частного партнерства в Таблицу показателей, характеризующих уровень развития ГЧП, уровень проектов территории города федерального значения, форму проекта, отрасль применения, объем инвестиций со стороны участников (Таблица 1). 
Таблица 1Развитие государственно-частного партнерства в СЗФО (г. Санкт-Петербург)

\begin{tabular}{|c|c|c|c|c|c|c|c|c|c|}
\hline \multicolumn{10}{|c|}{ Город федерального значения Санкт-Петербург } \\
\hline \multirow[b]{2}{*}{$\begin{array}{l}\mathbf{I} \\
/ \\
\mathbf{I I}\end{array}$} & \multirow[b]{2}{*}{ Наименование проекта } & \multicolumn{3}{|c|}{ Уровень проекта } & \multirow[b]{2}{*}{ Форма проекта } & \multirow[b]{2}{*}{ Отрасль } & \multicolumn{3}{|c|}{ Инвестиции (млн. руб.) } \\
\hline & & $\begin{array}{c}\text { Федераль- } \\
\text { ный }\end{array}$ & $\begin{array}{c}\text { Регио- } \\
\text { нальный } \\
\text { (межрег } \\
\text { иональн } \\
\text { ый) }\end{array}$ & $\begin{array}{l}\text { Муници- } \\
\text { альный }\end{array}$ & & & Общие & $\begin{array}{c}\text { Государст- } \\
\text { венные }\end{array}$ & Частные \\
\hline 1 & $\begin{array}{c}\text { Строительство и } \\
\text { эксплуатация } \\
\text { автомобильных дорог в } \\
\text { жилом районе } \\
\text { «Славянка» }\end{array}$ & - & + & - & $\begin{array}{l}\text { Соглашение о } \\
\text { ГЧП }\end{array}$ & $\begin{array}{l}\text { Транспорт, } \\
\text { автодороги }\end{array}$ & 47740,6 & 15913,5 & 31827,1 \\
\hline 2 & $\begin{array}{c}\text { Реконструкция аэропорта } \\
\text { «Пулково» }\end{array}$ & + & - & - & $\begin{array}{l}\text { Концессионное } \\
\text { соглашение }\end{array}$ & $\begin{array}{l}\text { Транспорт, } \\
\text { аэропорты }\end{array}$ & 55000,0 & 38000,0 & 17000,0 \\
\hline 3 & $\begin{array}{c}\text { Строительство и } \\
\text { эксплуатация } \\
\text { мусороперерабатывающе } \\
\text { го завода в Левашово }\end{array}$ & - & + & - & $\begin{array}{l}\text { Соглашение о } \\
\text { ГЧП }\end{array}$ & $\begin{array}{l}\text { Жилищно- } \\
\text { коммунальное } \\
\text { хозяйство, } \\
\text { отходы }\end{array}$ & 8000,0 & - & 8000,0 \\
\hline 4 & $\begin{array}{c}\text { Строительство } \\
\text { мультимодального } \\
\text { транчпортно- } \\
\text { пересадочного узла } \\
\text { «Девяткино» }\end{array}$ & - & $(+)$ & - & Не определена & $\begin{array}{l}\text { Транспорт, } \\
\text { логистика }\end{array}$ & $\begin{array}{l}\text { Не } \\
\text { определе } \\
\text { но }\end{array}$ & $\begin{array}{l}\text { Не } \\
\text { определе } \\
\text { но }\end{array}$ & $\begin{array}{l}\text { Не } \\
\text { опреде } \\
\text { лено }\end{array}$ \\
\hline 5 & $\begin{array}{c}\text { Строительство и } \\
\text { эксплуатация } \\
\text { образовательных } \\
\text { учреждений в жилом } \\
\text { районе «Славянка» }\end{array}$ & - & + & - & $\begin{array}{l}\text { Соглашение о } \\
\text { ГЧП }\end{array}$ & Образование & 3000,0 & 1500,0 & 1500,0 \\
\hline 6 & $\begin{array}{c}\text { «Невская вода»- } \\
\text { реконструкция Северной } \\
\text { водонапорной станции }\end{array}$ & - & + & - & $\begin{array}{l}\text { Соглашение о } \\
\text { ГЧП }\end{array}$ & $\begin{array}{l}\text { Жилищно- } \\
\text { коммунальное } \\
\text { хозяйство, } \\
\text { водоснабжение } \\
\text { и } \\
\text { водоотведение }\end{array}$ & 12000,0 & $\begin{array}{l}\text { Не } \\
\text { определе } \\
\text { но }\end{array}$ & $\begin{array}{l}\text { Не } \\
\text { опреде } \\
\text { лено }\end{array}$ \\
\hline 7 & $\begin{array}{c}\text { Западный скоростной } \\
\text { диаметр }\end{array}$ & - & + & - & $\begin{array}{l}\text { Концессионное } \\
\text { соглашение }\end{array}$ & $\begin{array}{l}\text { Транспорт, } \\
\text { автодороги }\end{array}$ & 81000,0 & - & 81000,0 \\
\hline 8 & $\begin{array}{c}\text { Строительство } \\
\text { Орловского тоннеля }\end{array}$ & - & + & - & $\begin{array}{l}\text { Отменен в связи } \\
\text { с удорожанием }\end{array}$ & $\begin{array}{l}\text { Транспорт, } \\
\text { автодороги }\end{array}$ & $\begin{array}{l}\text { Удорожа } \\
\text { ние } \\
\text { проекта }\end{array}$ & - & - \\
\hline & $\begin{array}{c}\text { Итого } 7 \text { проектов типа } \\
\text { ГЧІ }\end{array}$ & 1 & 6 & - & $\begin{array}{l}\text { Доминирует } \\
\text { соглашение о } \\
\text { ГЧП }\end{array}$ & $\begin{array}{l}\text { Доминирует } \\
\text { отрасль } \\
\text { транспорт, } \\
\text { автодороги }\end{array}$ & 186740,6 & 55413,5 & 66427,1 \\
\hline
\end{tabular}

В соответствии с Таблицей 1 , всего в городе федерального значения Санкт-Петербург в стадии реализации находится 7 проектов типа государственно-частного партнерства, один из них федерального и шесть - регионального уровня. Среди форм доминирует соглашение о ГЧП, концессионное соглашение, среди отраслей - транспорт, автодороги. Общий объем планируемых инвестиций - 186740,6 млн. руб., объем государственных и частных инвестиций из общего объема к настоящему времени окончательно не определен, пока их сумма составляет 55413,5 млн. руб. и 66427,1 млн. руб., соответственно, что не равно общему объему инвестиций.

В Санкт-Петербурге реализуется или планируется к реализации 7 проектов в типа государственно-частного партнерства, а в одиннадцати других субъектах СЗФО их число меньше (кроме Вологодской области, где 21 проект ГЧП). Архангельская область (5 проектов ГЧП), 
Калининградская область (4 проекта), Ленинградская область (4 проекта), Республика Карелия (7 проектов), Республика Коми (1), Псковская область (0), Новгородская область (0), Ненецкий АО (0), Мурманская область (0). В общей сложности сформировано 50 проектов ГЧП, один из которых - строительство Орловского тоннеля - отменен.

\section{ЛИТЕРАТУРА}

1. Угольникова О.Д., Петров А.П., Угольников В.В. Инновационная экономика: региональные кластерные инициативы. Монография. - СПб.: изд-во Санкт-Петербургского государственного университета сервиса и экономики, 2010. - 191 с.

2. Философова Т. Г., Быков В. А. Конкуренция. Инновации. Конкурентоспособность.- Издво: Юнити-Дана, 2012.- 295 с.

3. Королев В.А. Повышение квалификации государственных служащих: потенциал развития государственно-частного партнерства // Вопросы государственного и муниципального управления. 2008. №2. С. 182-195. 